\title{
ASUHAN KEBIDANAN KOMPREHENSIF PADA NY. "N" P2002 HARI KE-3 DENGAN BENDUNGAN ASI DI PUSKESMAS LAMONGAN TAHUN 2016
}

\author{
Husnul Muthoharoh* \\ *Dosen Program Studi Diploma III Kebidanan Universitas Islam Lamongan
}

\section{RINGKASAN}

Bendungan ASI merupakan sumbatan pada saluran ASI yang tidak dikosongkan seluruhnya dan sering terjadi pada hari ke-2 atau ke-3 ketika payudara telah memproduksi air susu. Dari data Puskesmas masih terdapat angka ibu nifas dengan bendungan ASI 16,5\%.

Tujuan penelitian ini adalah mendapat gambaran tentang penatalaksanaan Asuhan kebidanan komprehensif pada Ny. " $N$ " $\mathrm{P}_{2002}$ hari ke-3 dengan bendungan ASI di Puskesmas Lamongan.

Metode yang digunakan dalam penyusunan laporan hasil penelitian ini adalah deskripsi observasional yang dilaksanakan dengan pendekatan kohort mulai dari kehamilan sampai kontrasepsi diperoleh dari wawancara, pengkajian data primer, sekunder, pemeriksaan fisik.

Hasil penelitian didapatkan bahwa masih banyak ibu nifas yang mengalami kejadian bendungan ASI, terdapat kesenjangan antara teori dan fakta pada pengkajian suhu tubuh. Pengkajian suhu tubuh pada ibu nifas dengan bendungan ASI harusnya meningkat menjadi $>38^{\circ} \mathrm{C}$.

Upaya yang dapat dilakukan pada ibu untuk mengatasi bendungan ASI dengan cara melakukan perawatan payudara, mengompres payudara menggunakan air hangat \pm 5 menit, serta mengajari ibu cara menyusui yang benar.

\section{Kata Kunci : Asuhan Kebidanan, Bendungan ASI, Post partum}

\section{PENDAHULUAN}

Bendungan ASI merupakan terjadinya sumbatan pada saluran ASI yang tidak dikosongkan seluruhnya. Keadaan ini biasanya sering terjadi pada hari ke-2 atau ke3 ketika payudara telah memproduksi air susu.

Kurangnya pengetahuan ibu tentang perawatan payudara selama masa nifas dapat menyebabkan terjadinya bendungan ASI. Masa nifas masih potensial mengalami komplikasi sehingga perlu perhatian dari tenaga kesehatan, terutama ibuibu yang sosial ekonomi dan pendidikannya kurang, sering tidak mengerti potensi bahaya masa nifas (Saifudin, 2009).

Masa nifas merupakan masa post partum atau waktu sejak bayi dilahirkan dan plasenta keluar lepas dari rahim, sampai enam minggu berikutnya, disertai dengan pulihnya kembali organ-organ yang berkaitan dengan kandungan (Saleha, 2009).

Pada tahun 2015 di Amerika Serikat sekitar $60 \%$ para ibu menyusui bayinya, dari $60 \%$ terdapat $22 \%$ yang memberikan ASI ekslusif. Hal tersebut tidak sesuai dengan harapan, dimana target pada tahun 
2015 adalah sekitar 75\% ibu dapat menyusui bayinya secara ekslusif.

Sedangkan di Indonesia angka kejadian Bendungan ASI terbanyak terjadi pada ibu-ibu bekerja sebanyak 16\% dari ibu menyusui (Departemen Kesehatan RI, 2015)

Berdasarkan hasil Survey tahun 2015 di Jawa Timur, kejadian bendungan ASI pada ibu menyusui di JawaTimur yaitu $1-3 \%$ (1-3 kejadian dari 100 ibu menyusui) terjadi di perkotaan dan 2-13\% (2-13 kejadian dari 100 ibu menyusui) terjadi di pedesaan (Badan Pusat Statistik Propinsi Jawa Timur, 2015). Sedangkan data dari Dinas Kesehatan Kabupaten Lamongan pada tahun 2015 terdapat 1.320 jiwa ibu nifas, dan ibu nifas fisiologis 1.131 jiwa $(85,7 \%)$ dengan kasus perdarahan sebanyak 44 kasus $(3,4 \%)$, kasus hipertensi sebanyak 77 kasus $(5,9 \%)$ kasus infeksi luka SC sebanyak 47 kasus $(3,6 \%)$ kasus dengan bendungan asi 20 kasus $(1,6 \%)$ kasus mastitis sebanyak 9 kasus $(0,7 \%)$ (Dinas Kesehatan Kabupaten Lamongan, 2016).

Berdasarkan data yang diperoleh dari Buku Register Ruang KIA Puskesmas Lamongan pada tahun 2016 bulan januari-juni berjumlah 629 orang. Dari data tersebut ibu nifas dengan komplikasi sebanyak 80 pasien $(12,7 \%)$, terjadi komplikasi nifas yaitu Bendungan ASI 73 pasien $(11,6 \%)$ disebabkan oleh beberapa hal antara lain puting susu terbenam 11 pasien $(3,4 \%)$, reflek sucking negative 27 pasien $(4,2 \%)$, saluran duktus laktiferus tersumbat 20 pasien $(6,1 \%)$, puting terlalu panjang 8 pasien $(2,5 \%)$ dan payudara lecet 7 pasien $(2,2 \%)$.

Bendungan ASI terjadi karena beberapa faktor diantaranya yaitu teknik yang salah dalam menyusui, puting susu terbenam, bayi tidak dapat menghisap puting dan aerola, ibu yang tidak menyusukan bayinya sesering mungkin atau bayi yang tidak aktif menghisap. Diantara beberapa faktor penyebab diatas jika tidak segera ditangani akan berakibat ke mastitis (Rukiyah, 2010)

$$
\text { Bendungan ASI dapat }
$$
disebabkan oleh pengeluaran ASI yang tidak lancar, bayi tidak disusukan secara teratur, cukup sering menyusui atau telalu cepat disapih (Arif Mansjoer, dkk, 2008). Bendungan ASI disebabkan oleh pengeluaran air susu yang tidak lancar, karena bayi tidak cukup sering menyusu, produksi meningkat, terlambat menyusukan, hubungan dengan bayi kurang baik, dan dapat pula karena adanya pembatasan waktu dalam menyusui (Prawirohardjo, 2009).

Untuk mencegah terjadinya bendungan ASI, maka petugas kesehatan sebaiknya melakukan penyuluhan pada ibu nifas dan ibu hamil tentang menyusui secara dini, menyusui bayi segera mungkin (sebelum 30 menit) setelah dilahirkan, menyusui bayi tanpa dijadwal, keluarkan ASI dengan tangan atau pompa bila produksi melebihi kebutuhan bayi, perawatan payudara pasca persalinan dan hindari tekanan lokal pada payudara serta memberikan Health Education pada ibu nifas dan ibu hamil untuk menyusui bayinya secara eksklusif.

\section{TUJUAN PENELITIAN}

Tujuan penelitian ini adalah mendapat gambaran tentang penatalaksanaan Asuhan kebidanan komprehensif pada $\mathrm{Ny}$. "N" $\mathrm{P}_{2002}$ hari ke-3 dengan bendungan ASI di Puskesmas Lamongan 
Masa nifas (Puerperium) ialah masa sesudah persalinan yang diperlukan untuk pulihnya kembali alat kandungan yang lamanya 6 minggu (Sastrawinata, 2006). Masa nifas atau puerperium yaitu masa yang dimulai sejak 1 jam setelah lahirnya plasenta sampai dengan 6 minggu (Prawirohardjo, 2009).

Bendungan ASI merupakan istilah terjadinya sumbatan pada saluran ASI yang tidak dikosongkan seluruhnya. Keadaan ini biasanya sering terjadi pada hari ke-2 atau ke3 ketika payudara telah memproduksi air susu (Saifudin, 2009).

Bendungan ASI adalah pembendungan air susu karena penyempitan duktus lakteferi atau kelenjar-kelenjar tidak dikosongkan dengan sempurna atau karena kelainan pada putting susu (Mochtar, 2008).

Bendungan ASI dapat terjadi pada hari kedua atau ketiga ketika payudara telah memproduksi air susu Bendungan ASI disebabkan oleh pengeluaran air susu yang tidak lancar, karena bayi tidak cukup sering menyusu, produksi meningkat, terlambat menyusukan, hubungan dengan bayi (bounding) kurang baik, dan dapat pula karena adanya pembatasan waktu menyusui (Prawirohardjo, 2009).

Penanganan yang dilakukan yang paling penting adalah dengan mencegah terjadinya payudara bengkak dengan cara: menyusui bayi segera setelah lahir, menyusui bayi tanpa dijadwal, mengeluarkan sedikit ASI sebelum menyusui agar payudara lebih lembek, mengeluarkan ASI dengan tangan atau pompa bila produksi melebihi kebutuhan ASI, melakukan perawatan payudara setelah melahirkan (Rukiyah, 2010).

\section{METODE PENELITIAN}

Metode yang digunakan dalam penyusunan laporan hasil penelitian ini adalah deskripsi observasional yang dilaksanakan dengan pendekatan kohort mulai dari kehamilan sampai kontrasepsi diperoleh dari wawancara, pengkajian data primer, sekunder, pemeriksaan fisik.

\section{PEMBAHASAN}

Setelah penulis melakukan Asuhan Kebidanan Komprehensif Pada Ny. "N" $\mathrm{P}_{2002}$ hari ke-3 dengan Bendungan ASI di Puskesmas Lamongan di dapatkan ada atau tidak adanya kesenjangan dari teori dengan kenyataan sebagai berikut :

\section{Pengkajian Data Subyektif}

Pada data subyektif terdapat kesenjangan untuk pola aktivitas. Pada kasus disebutkan ibu melakukan pekerjaan rumah tangga yang ringan saja seperti menyapu, mengepel, dan memasak. Pada teori bendungan ASI dapat menganggu pola aktivitas sehari-hari dikarenakan adanya nyeri sehingga tidak dapat melakukan aktivitas seperti biasanya.

Untuk tidak terjadinya nyeri sehingga pola aktivitas tidak terganggu sebaiknya ibu melakukan mobilisasi dini agar tidak terjadi nyeri sehingga tidak mengganggu pola aktivitas.

Di kuatkan pada teori bahwa presentase pengaruh pola aktivitas terhadap bendungan ASI sebesar 25\% (Manuaba, 2010).

\section{Pengkajian Data Obyektif}

Pada data obyektif terdapat kesejangan untuk tanda-tanda vital. 
Pada kasus disebutkan tanda-tanda vital pada suhu $37,9^{\circ} \mathrm{C}$. Pada teori disebutkan suhu tubuh meningkat $>38^{\circ} \mathrm{C}$.

Untuk tidak meningkatnya suhu tubuh pada kasus bendungan ASI sebaiknya ibu mengkompres payudara selama \pm 5 menit sehingga tidak terjadi peningkatan suhu tubuh.

Dikuatkan oleh teori bahwa tanda dan gejala pada kasus bendungan ASI suhu tubuh meningkat $>38^{\circ} \mathrm{C}$ (Rukiyah, 2010).

\section{Analisa}

Pada analisa terdapat persamaan untuk masalah aktual. Pada kasus disebutkan terdapat nyeri pada payudara, suhu tubuh meningkat, dan ASI tidak keluar. Pada teori disebutkan nyeri pada payudara, suhu tubuh meningkat, dan ASI tidak keluar.

Untuk tidak terjadi tanda dan gejala seperti nyeri payudara, suhu tubuh meningkat dan ASI tidak keluar sebaiknya dilakukan perawatan payudara sehingga tanda dan gejala bias teratasi.

Dikuatkan pada teori bahwa Cucilah tangan sebelum memassase. Lalu tuangkan minyak kedua belah telapak tangan secukupnya. Pengurutan dimulai dengan ujung jari, caranya: Sokong payudara kiri dengan tangan kiri. Lakukan gerakan kecil dengan dua atau tiga jari tangan kanan, mulai dari pangkal payudara dan berakhir dengan gerakan spiral pada daerah putting susu. Selanjutnya buatlah gerakan memutar sambil menekan dari pangkal payudara dan berakhir pada putting susu di seluruh bagian payudara. Gerakan selanjutnya letakkan kedua telapak tangan di antara dua payudara. Urutlah dari tengah ke atas sambil mengangkat kedua payudara dan lepaskan keduanya perlahan. Lakukan gerakan ini kurang lebih 30 kali. Lalu cobalah posisi tangan pararel. Sanggah payudara dengan satu tangn, sedangkan tangan lain mengurut payudara dengan sisi kelinking dari arah pangkal payudara kearah putting susu. Lakukan gerakan ini sekitar 30 kali. Setelah itu letakkan satu tangan di sebelah atas dan satu lagi dibawah payudara. Luncurkan kedua tangan bersamaan ke arah putting susu dengan cara memutar tangan. Ulangi gerakan ini sampai semua bagian payudara terkena urutan (Suherni, 2009).

\section{Penatalaksanaan}

Pada penatalaksanaan terdapat persamaan pada tinjauan teori dan tinjauan kasus. Pada tinjauan kasus disebutkan bahwa menjelaskan pada pasien dan keluarga hasil pemeriksaan, menjelaskan tentang penyebab bendungan ASI, menjelaskan pada ibu dan keluarga tentang komplikasi yang mungkin timbul misalnya mastitis, menganjurkan ibu untuk menyusui bayi sesering muingkin tanpa jadwal, menganjurkan ibu untuk mengkonsumsi sayuran hijau, mengajarkan kepada ibu cara perawatan payudara, mengajarkan kepada ibu cara meneteki yang benar,memberikan ibu pengobatan, mendekontaminasikan asuhan yang diberikan. Pada teori disebutkan bahwa menjelaskan pada pasien dan keluarga hasil pemeriksaan, menjelaskan tentang penyebab bendungan ASI, menjelaskan pada ibu dan keluarga tentang komplikasi yang mungkin timbul misalnya mastitis, menganjurkan ibu untuk menyusui bayi sesering muingkin tanpa jadwal, menganjurkan ibu 
untuk mengkonsumsi sayuran hijau, mengajarkan kepada ibu cara perawatan payudara, mengajarkan kepada ibu cara meneteki yang benar, memberikan ibu pengobatan, mendekontaminasikan asuhan yang diberikan. Untuk mengatasi penatalaksanaan pada bendungan ASI sebelumnya harus mengetahui faktor penyebab dari bendungan ASI terlebih dahulu.

Dikuatkan oleh teori yang timbul pada Bendungan ASI, yaitu pengosongan mamae yang tidak sempurna, faktor hisapan bayi yang tidak aktif, faktor posisi menyusui bayi yang tidak benar, puting susu terbenam. puting susu terlalu panjang (Saifudin, 2009).

\section{KESIMPULAN}

Setelah melakukan asuhan kebidanan pada Ny "N" $\mathrm{P}_{2002}$ hari ke-3 dengan Bendungan ASI di Puskesmas Lamongan, maka didapatkan kesimpulan :

1. Masih banyak ibu nifas yang mengalami kejadian bendungan ASI

2. Terdapat kesenjangan antara teori dan fakta pada pengkajian suhu tubuh. Pengkajian suhu tubuh pada ibu nifas dengan bendungan ASI harusnya meningkat menjadi $>38^{\circ} \mathrm{C}$

3. Upaya yang dapat dilakukan pada ibu untuk mengatasi bendungan ASI dengan cara melakukan perawatan payudara, mengompres payudara menggunakan air hangat \pm 5 menit, serta mengajari ibu cara menyusui yang benar.

\section{Saran}

Bagi Teoritis. Dapat dijadikan sebagai bahan masukan atau tambahan untuk perkembangan dan penyempurnaan asuhan yang sudah ada.

Bagi Institusi. Diharapkan dapat menyediakan lebih banyak literatur dengan tahun terbaru dalam menyusun Laporan Tugas Akhir khususnya kasus ibu nifas dengan bendungan ASI.

Bagi Lahan Praktek. Diharapkan dapat meningkatkan kualitas pelayanan bagi petugas dan klien sehingga tercapai asuhan kebidanan yang lebih komprehensif

\section{DAFTAR PUSTAKA}

Manuaba, Ida Ayu Chandranita, dkk. 2010. Ilmu Kebidanan, Penyakit Kandungan dan KB. Jakarta: EGC

Mochtar, Rustam. 2008. Sinopsis Obstetri. Jakarta: EGC

Prawirohardjo, Sarwono. 2009. Ilmu Kebidanan. Jakarta: Yayasan Bina Pustaka

Rukiyah, Ai Yeyeh, dkk. 2010. Asuhan Kebidanan Patologi Kebidanan. Jakarta Timur: CV. Trans Info Media

Saifuddin, Abdul Bari. 2009. Buku Acuan Nasional Pelayanan Kesehatan Maternal dan Neonatal. Jakarta: PT. Bina Pustaka Sarwono Prawirohardjo

Saifuddin, Abdul Bari. 2009. Panduan Praktis Pelayanan Kesehatan Maternal dan Neonatal. Jakarta: EGC 
Saleha, Siti. 2009. Asuhan

Kebidanan Pada Masa

Nifas. Jakarta: Salemba

Medika

Sastrawinata, Sulaiman. 2006:

Obstetri fisiologis.

Bandung: ELEMAN

Suherni, dkk. 2009: Perawatan masa nifas. Yogyakarta:

Fitramaya 